\title{
Development of Acacia Glulam Wood Exterior Beam-to-Column Connection with Angles and Steel Rods System
}

\author{
Djoni Simanta ${ }^{1}$, Bambang Suryoatmono ${ }^{1, *}$, and Johannes A. Tjondro ${ }^{1}$ \\ ${ }^{1}$ Departmentof Civil Engineering, Parahyangan Catholic University, Indonesia
}

\begin{abstract}
In this paper, two models (M9B1 and M9B2 connection types) of acacia glulam wood exterior beam-to-column connections with angles and steel rod system have been developed. Both models have been tested experimentally under monotonic static and cyclic loadings. The behaviour of each model under static and cyclic loadings, maximum displacement, maximum moment, equivalent viscous damping ratio, stiffness degradation, rotational stiffness and ductility have been observed. From the test results it can be concluded that the behaviour of the connections were influenced by the number of bearing steel rods at the beam, wood quality, and thickness of the angles. The M9B1 connection type has more flexibility than the M9B2 connection type. Three dimensional finite element analyses considering anisotropic plasticity have been conducted for both models. It can be concluded that in M9B1 connection type, the tensile forces due to the moment are received by the combination of tensile steel rods and bearing force in the steel rod and wood around it. Overall performance of M9B2 connection type is better than that of M9B1 connection type because the former has higher initial stiffness and higher rotational ductility than the later.
\end{abstract}

\section{Introduction}

In an earthquake resistant timber buildings, one of the important details that needs to be considered is the beam-to-column connections. The connections need to be able to dissipate energy effectively. Moreover, they have to have enough rotation capacity and ductility so that moment redistribution can occur in the building. Several studies have been done to obtain wood beam-to-column connections. A portal quick connection is a semi-rigid moment connection developed by Scheibmair and Queneville [1]. The connection has a concept similar to the usual bolted partial moment connections used in steel structures. The connection consisted of steel rods. Test results of this type of connection showed that failure modes were tension parallel to the grain, shear failure, tension perpendicular to the grain, and bearing failure in the contact area between the beam and the column. Another connection type is dowel moment connection developed by Leitner [2] as seen in Figure 1. It can be seen in the figure that: (a) the initial stiffness and degradation of the stiffness of

\footnotetext{
*Corresponding author: suryoatm@unpar.ac.id
} 
the two models is very different, (b) pinching occurs in experimental cyclic test results, and (c) the plastic behaviour of the material is not modelled sufficiently in the numerical model.
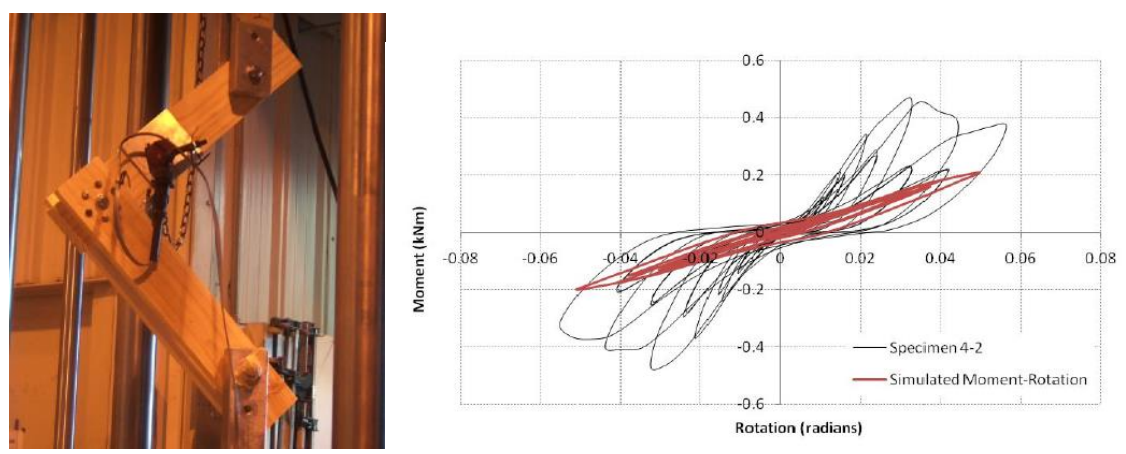

Fig. 1. Moment connection developed by Leitner under cyclic loading (a) Experimental setup, (b) hysteretic loop of experimental test and finite element analysis [2]

In this paper, two models (M9B1 and M9B2 connection types) of acacia glulam wood exterior beam-to-column connections with angles and steel rod system have been developed. What is meant by the exterior connection here does not mean the connection is exposed to the weather, but the connection between the column and the beam exists only on one side of the column. The first model uses one dowel steel rod parallel to the grain and the second one uses two dowel steel rood parallel to the grain. Figure 2 and 3 show the dimensions of M9B1 and M9B2 models, respectively. The presence of steel rod and steel angle in each model is intended to add its ductility. Both models have been tested experimentally and numerically under monotonic static and cyclic loadings. The maximum displacement, maximum moment, equivalent viscous damping ratio, stiffness degradation, rotational stiffness, and ductility have been observed. Simanta et.al [3] discusses the experimental results in more detail. On the other hand, this paper discusses the numerical (finite element) analysis results.
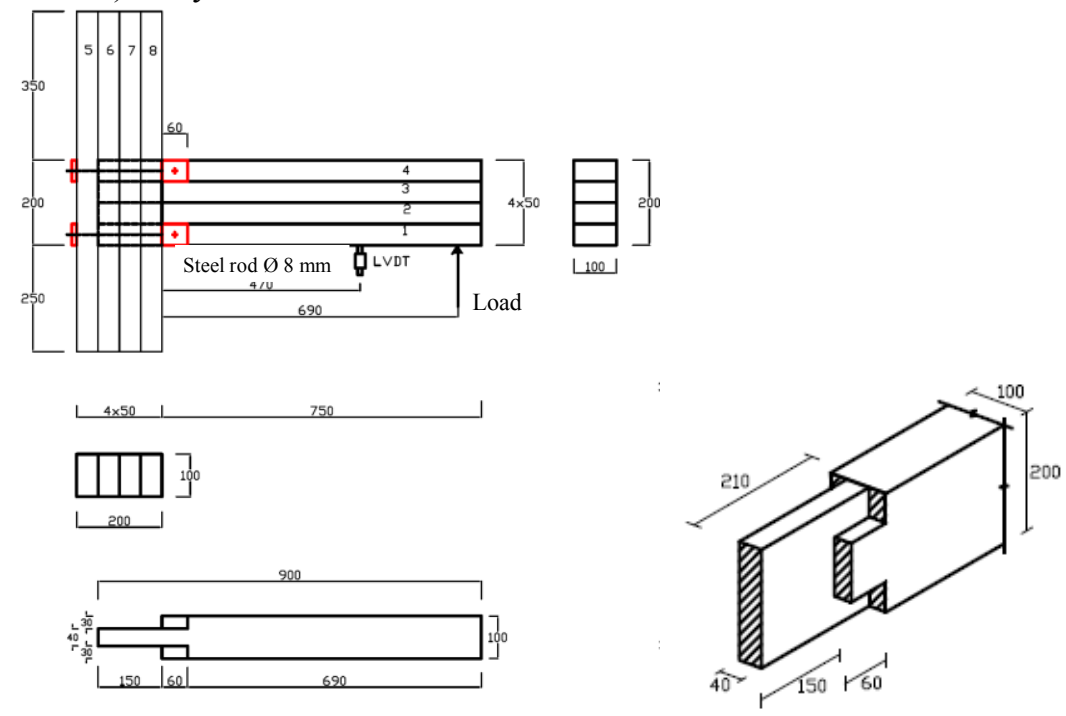

Fig. 2. Dimensions of beam-to-column connection with one steel rod in the beam, type M9B1. 

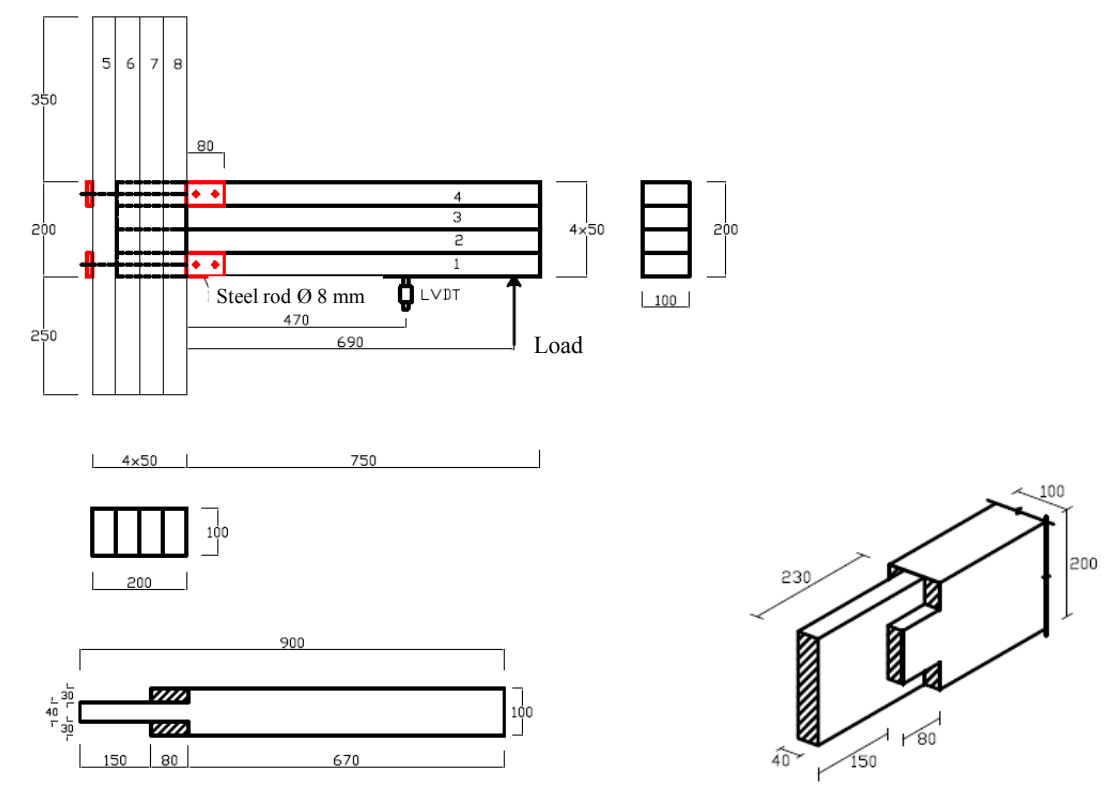

Fig. 3. Dimensions of beam-to-column connection with two steel rods in the beam, type M9B2.

Both types of connection basically use the concept in the steel structure connection, where the bending moment is received by the tensile steel. Then, the tensile force is transferred by a sufficiently rigid steel angle to the lateral steel rods providing a bearing strength to the glulam beam section. The shear force is assumed to be carried by a rigid shear key in the form of a wooden pen that is part of a glulam wood beam that pierces the column. Figure 4 shows the picture of the developed beam-to-column connection.

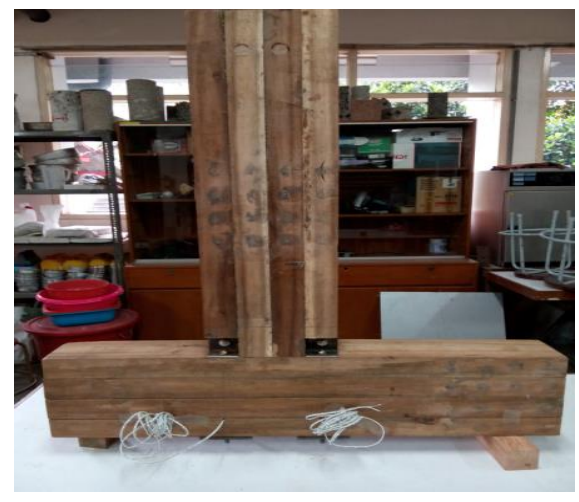

(a)

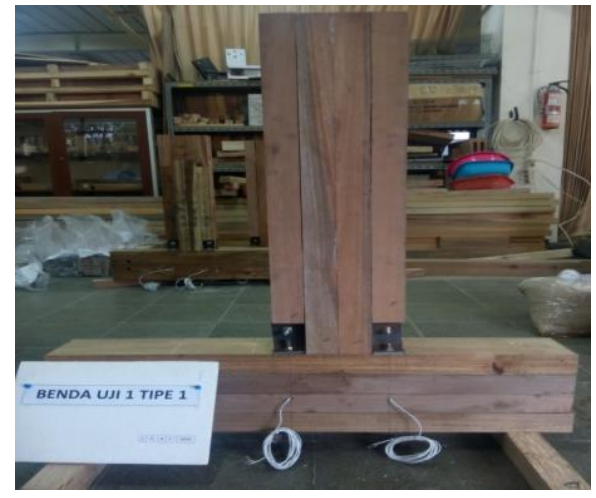

(b)

Fig. 4. Acacia glulam wood exterior beam-to-column connection with angles and steel rods system, (a) M9B1 connection type, (b) M9B2 connection type [3].

\section{Non-linear finite element analysis (FEA)}

Experimental tests of wood connections in general require the availability of wood which is quite a lot and requires a considerable cost. Therefore, the use of a nonlinear finite element program capable of simulating the $3 \mathrm{D}$ model of the connection would be very useful in the research to complement the experimental test results. The finite element program needed to 
simulate the behaviour of the beam-to-column connection developed in this paper is the one capable of modelling orthotropic, transverse isotropic and anisotropic plasticity behaviour for wood materials, and various contact behaviour between each part of the connection. Non-linear finite element analysis was performed using ANSYS version 15, or specifically ANSYS Workbench as a CAD system that facilitated the modelling of complex geometric shapes. ANSYS Workbench automatically establishes contact elements and performs meshing according to the geometry of the elements modelled through its designer model. The results of this finite element analysis are compared with experimental results.

The 3D non-linear finite element analysis to study the behaviour of the beam-to-column connection utilizes SOLID45 element with 8 nodes as seen in Figure 5. In this SOLID45 element the plasticity condition is characterized by reversible strain that occurs in a material when a given stress level is achieved by defining the bilinear stress-strain relation as seen in Figure 6 .
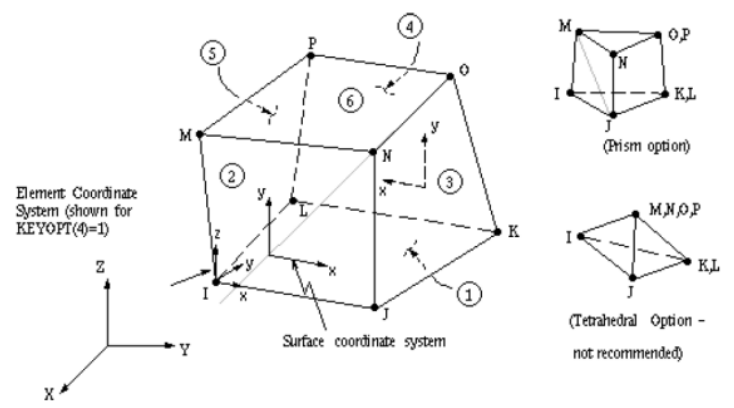

Fig. 5. Element SOLID45 with 8 nodes in ANSYS used in finite element analysis of the beam-tocolumn connection [4].

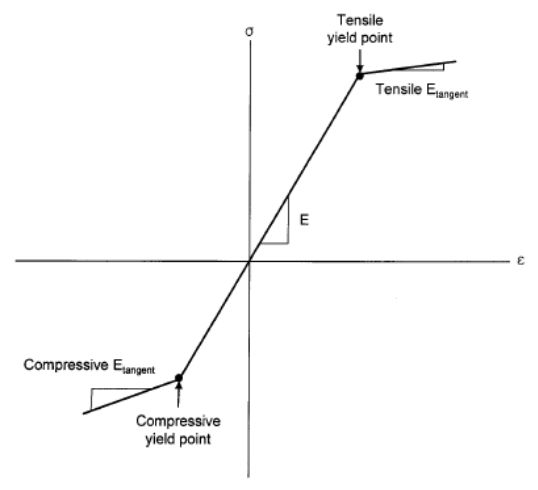

Fig. 6. Bilinear stress-strain relation in anisotropic plastic behaviour model [5]

\subsection{Wood mechanical properties}

The wood orthotropic properties used as input data for the finite element analysis using ANSYS are expressed in the $L$ (longitudinal), $R$ (radial), and $T$ (tangential) directions as seen in Table 1. The values are obtained from the compression test parallel and perpendicular to the grain according to ASTM D143 [6]. Wood mechanical properties for considering bearing obtained from test results according to ASTM D5764 [7] and used in finite analysis are shown in Table 2 . The wood lamina identified as $A, C, D, E, F, G, H$ and $I$ are the wood lamina used to form glulam columns and beams in the tested beam-tocolumn connection and modelled in the finite element analysis. To account for the strain 
hardening of the compressive moduli of elasticity $\left(E_{L}, E_{T}\right.$, and $\left.E_{R}\right)$ and shear moduli $\left(G_{L T}\right.$, $G_{R T}$ ), all moduli are multiplied by 0.01 [5].

Table 1. Orthotropic properties of wood in finite element analysis.

Moduli and stresses are in MPa.

\begin{tabular}{|c|c|c|c|c|c|c|c|c|c|c|c|c|c|}
\hline Lamina & $E_{L}$ & $E_{T}=E_{R}$ & $\sigma_{L}$ & $\sigma_{T}=\sigma_{R}$ & $v_{L T}$ & $v_{R T}$ & $v_{T L}$ & $G_{L T}$ & $G_{R T}$ & $\boldsymbol{V}_{L T}$ & $\boldsymbol{Y}_{R T}$ & $\tau_{L T}$ & $\tau_{R T}$ \\
\hline A & 7242.64 & 459.00 & 26.54 & 8.55 & 0.29 & 0.43 & 0.02 & 850.32 & 160.02 & 0.01 & 0.02 & 5.88 & 13.55 \\
\hline C & 5734.38 & 919.58 & 36.18 & 8.52 & 0.30 & 0.35 & 0.05 & 1026.74 & 339.58 & 0.00 & 0.01 & 4.55 & 7.90 \\
\hline D & 8020.05 & 511.83 & 49.09 & 9.94 & 0.34 & 0.26 & 0.02 & 933.96 & 202.37 & 0.01 & 0.02 & 6.78 & 14.57 \\
\hline E & 4569.92 & 388.46 & 26.31 & 7.17 & 0.20 & 0.28 & 0.02 & 628.74 & 151.43 & 0.01 & 0.01 & 4.61 & 9.39 \\
\hline F & 9537.34 & 497.57 & 46.96 & 7.25 & 0.21 & 0.28 & 0.01 & 1038.53 & 194.36 & 0.01 & 0.01 & 5.29 & 12.23 \\
\hline G & 7676.45 & 584.13 & 39.53 & 14.13 & 0.32 & 0.37 & 0.02 & 972.09 & 212.56 & 0.01 & 0.02 & 9.20 & 19.68 \\
\hline H & 7705.64 & 924.15 & 44.12 & 13.86 & 0.19 & 0.15 & 0.02 & 1253.06 & 401.63 & 0.01 & 0.01 & 8.15 & 14.40 \\
\hline I & 7846.15 & 338.23 & 35.36 & 6.59 & 0.31 & 0.41 & 0.01 & 764.82 & 119.71 & 0.01 & 0.02 & 5.01 & 12.66 \\
\hline
\end{tabular}

Table 2. Orthotropic properties of bearing wood in finite element analysis. Moduli and stresses are in MPa.

\begin{tabular}{|c|c|c|c|c|c|c|c|c|c|c|c|c|c|}
\hline Wood & $\boldsymbol{E}_{\boldsymbol{L}}$ & $\boldsymbol{E}_{\boldsymbol{T}}=\boldsymbol{E}_{\boldsymbol{R}}$ & $\boldsymbol{\sigma}_{\boldsymbol{L}}$ & $\boldsymbol{\sigma}_{\boldsymbol{T}}=\sigma_{\boldsymbol{R}}$ & $\boldsymbol{v}_{\boldsymbol{L} \boldsymbol{T}}$ & $\boldsymbol{v}_{\boldsymbol{R} \boldsymbol{T}}$ & $\boldsymbol{v}_{\boldsymbol{T} \boldsymbol{L}}$ & $\boldsymbol{G}_{\boldsymbol{L} \boldsymbol{T}}$ & $\boldsymbol{G}_{\boldsymbol{R} \boldsymbol{T}}$ & $\boldsymbol{\Upsilon}_{\boldsymbol{L} \boldsymbol{T}}$ & $\boldsymbol{\Upsilon}_{\boldsymbol{R} \boldsymbol{T}}$ & $\boldsymbol{\tau}_{\boldsymbol{L} \boldsymbol{T}}$ & $\boldsymbol{\tau}_{\boldsymbol{R} \boldsymbol{T}}$ \\
\hline $\mathrm{E}$ & 370.11 & 221.38 & 42.26 & 19.11 & 0.20 & 0.28 & 0.12 & 123.59 & 86.30 & 0.06 & 0.07 & 7.21 & 8.63 \\
\hline $\mathrm{H}$ & 609.21 & 333.79 & 62.00 & 27.90 & 0.19 & 0.15 & 0.10 & 198.03 & 145.06 & 0.05 & 0.06 & 10.85 & 12.68 \\
\hline
\end{tabular}

\subsection{Steel mechanical properties}

In the finite element analysis to obtain the behaviour of beam-to-column connection developed in this paper, the type of elements used to model steel rods and steel angle are SOLID186 and SOLID187. To take into account the plasticity in the analysis, stress-strain curve of steel tensile test results used in the ANSYS data is multi-linear isotropic hardening curve as seen in Figure 7. The curve is used as material property of steel rods. For steel angle, the material is assumed to behave as perfectly plastic isotropic material, with material properties as follows: yield stress $F_{y}=250 \mathrm{MPa}$, modulus of elasticity $E=200000$ $\mathrm{MPa}$, and strain hardening factor $=0$.

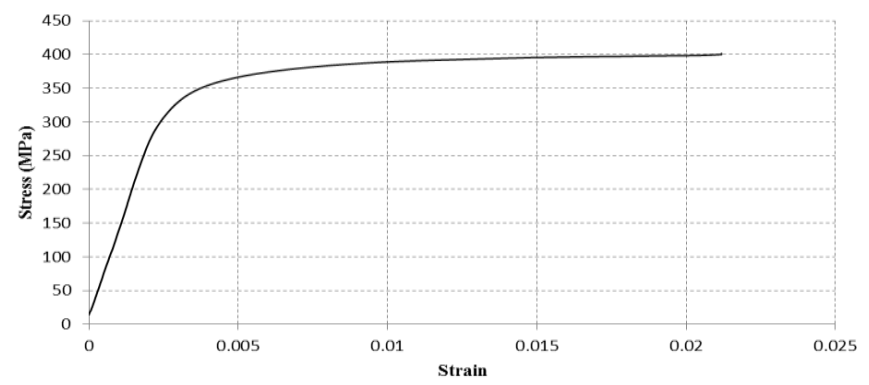

Fig. 7. Multi-linear isotropic hardening stress (MPa) - strain curve for modelling steel rods. 


\subsection{Modelling the connection for Finite Element Analysis}

Finite element mesh to model the beam-to-column connection is generated using ANSYS Workbench. Example of the mesh is shown in Figure 8. In ANSYS Workbench there are some basic options of the contact surface model that can be applied to the finite element model. It is very important to utilize the closest assumption to the reality.

Fully bonded between two surfaces assumes that the contact between both surfaces is perfectly attached so that there is no penetration, no separation and no sliding between both surfaces. Fully bonded is used in modelling contact between each wood lamina in glulam beam and column, between the steel angle and the nut, between the steel bar and the nut, and between the outer lamina of the column and the nut.

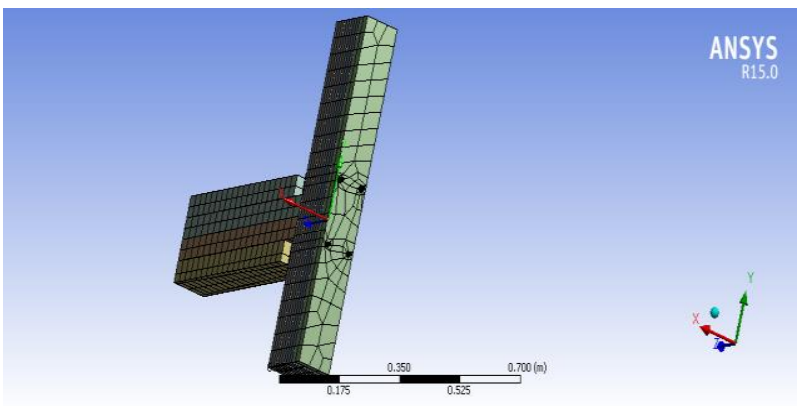

Fig. 8. Example of finite element mesh for studying the behaviour of the beam-to-column connection.

Between the beam pen and the column lamina surrounding it and between the beam lamina and steel angle, it is assumed that no separation exists between the surfaces. This means that one surface can slip without friction along the contact surface but both surfaces cannot separate.

In frictionless model there is no penetration on the contact surface, but both surfaces can slip without friction, and the formation of gap between both surfaces is allowed. Frictionless model is used in the contact surfaces between the column lamina and the steel rod, and in the contact surfaces of the column lamina with the steel angle.

In a situation where contact between surfaces cannot be modelled in ANSYS, it is suggested to use suppressed model. This means that contact between the two surfaces is not activated. Suppressed model is used in contact between steel angle and steel rods, between bearing steel rod and bearing wood in beam, and between steel angle and column.

There are two loading conditions applied to each finite element model, namely static monotonic and cyclic loadings in the form of line load at the beam end. The cyclic load applied to the connection is in accordance to the cyclic load of ISO [8] as seen in Figure 9.

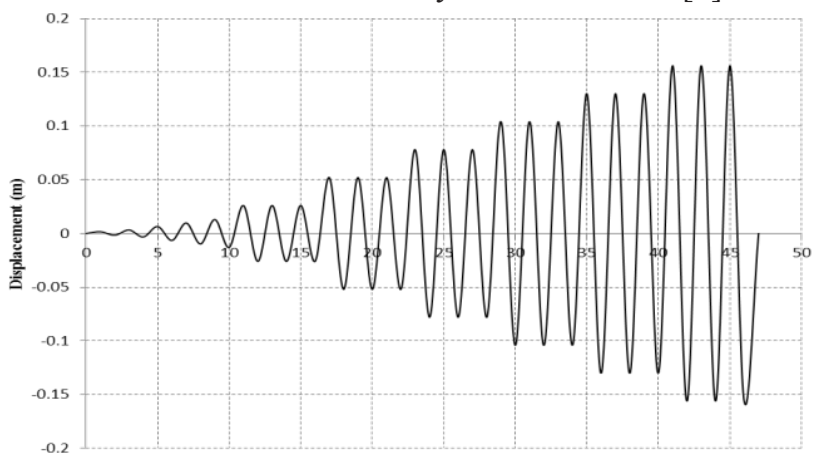

Fig. 9. Cyclic loading of ISO for wood beam-to-column connection [8]. 
Boundary conditions used in the finite element model are fixed support and frictionless support to model the supports at the top and bottom of the column, respectively.

Nonlinearity in the nonlinear finite element solution occurs because the analysis uses nonlinear material behaviour (plasticity) and contact surfaces between each part of the solid model. Nonlinear analysis solutions generally use iteration. In ANSYS Workbench, this iteration is performed using Newton-Raphson Method.

There are six connection models analysed depending on the lamina in the glulam column and beam as seen in Table 3. Two models are of the M9B1 type that has one bearing steel rod and four models are of the M9B2 type that has two bearing steel rods. As an example, Figure 10 shows all lamina in M9B1_L_1 model. See Table 1 for the material properties of each lamina identified as A, C, D, E, F, G, H, and I. For lamina of beam surrounding the steel rod, the material properties used in the analysis is shown in Table 2.

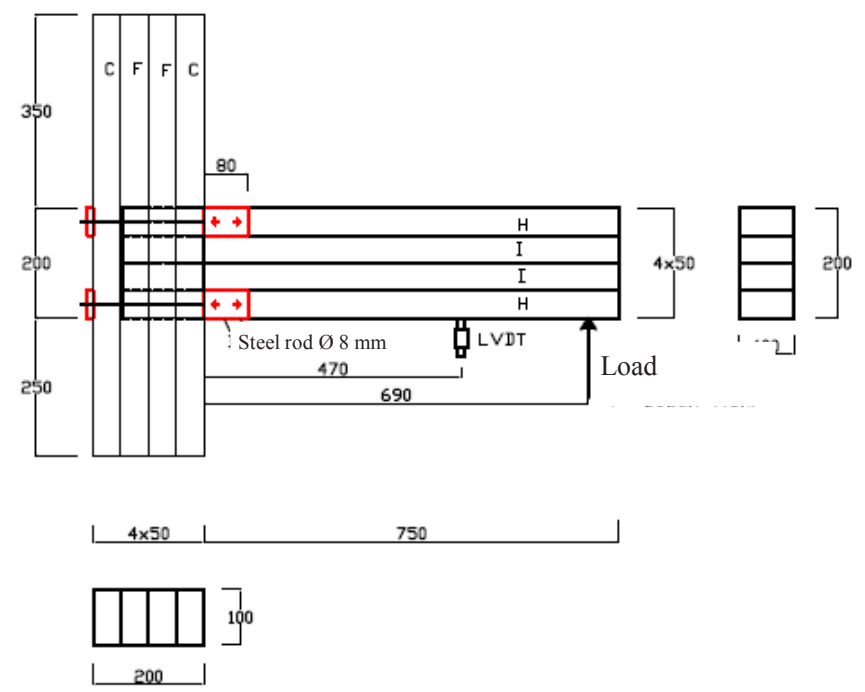

Fig. 10. Lamina in glulam column and beam for finite element model identified as M9B1_L_1.

Table 3. Lamina for glulam column and beam in each model.

\begin{tabular}{|c|c|c|}
\hline Identity* & $\begin{array}{c}\text { Column lamina from } \\
\text { left to right }\end{array}$ & $\begin{array}{c}\text { Beam lamina from top } \\
\text { to bottom }\end{array}$ \\
\hline M9B1_L_1 & C-F-F-C & H-I-I-H \\
\hline M9B1_L_2 & A-A-G-G & E-D-D-E \\
\hline M9B2_L_1 & C-F-F-C & H-I-I-H \\
\hline M9B2_L_2 & A-A-G-G & E-D-D-E \\
\hline M9B2_L_3 & C-F-F-C & H-I-I-H \\
\hline M9B2_L_4 & A-A-G-G & E-D-D-E \\
\hline
\end{tabular}

$* \mathrm{~L}$ stands for lamina

\section{Results and discussion}

From each finite element analysis of beam-to-column connection, load - displacement curve can be obtained. By using simple statics, the load - displacement curve can be converted into moment - rotation curve. The moment is obtained by multiplying the load by the distance between the face of the column and the load position. The rotation is obtained by dividing the deflection by the distance between the face of the column and the load position. Figure 11 shows load - displacement curve of M9B1_L_1 and M9B1_L_2 
obtained from non-linear finite element analysis under monotonic loading condition, as an example. Experimental results [3] for the same models are also shown in the figure. Figure 12 shows the moment - rotation curve for the same models as the ones in Figure 11. In Figure 12, the moment - rotation curves for both models under cyclic loading are also plotted for comparison.

It can be seen from Figures 11, 13, and 14 that for both M9B1 and M9B2 connections, FEA gives higher load (and hence moment) carrying capacity compared to experimental results. On the other hand, experimental results show larger ductility compared to FEA results. Furthermore, from Figure 12, it is seen that the plasticity of M9B1 connection has occurred. However, the cyclic loading results of FEA could not show the expected hysteretic loop as usually happens in a beam-to-column connection. The same phenomenon is also seen in M9B2 connection type. This is partly because the FEA could not model both micro-cracks and macro-cracks that occurred in the experimental tests. Note that the static loading curve in Figure 12 is obtained by assuming an odd function.

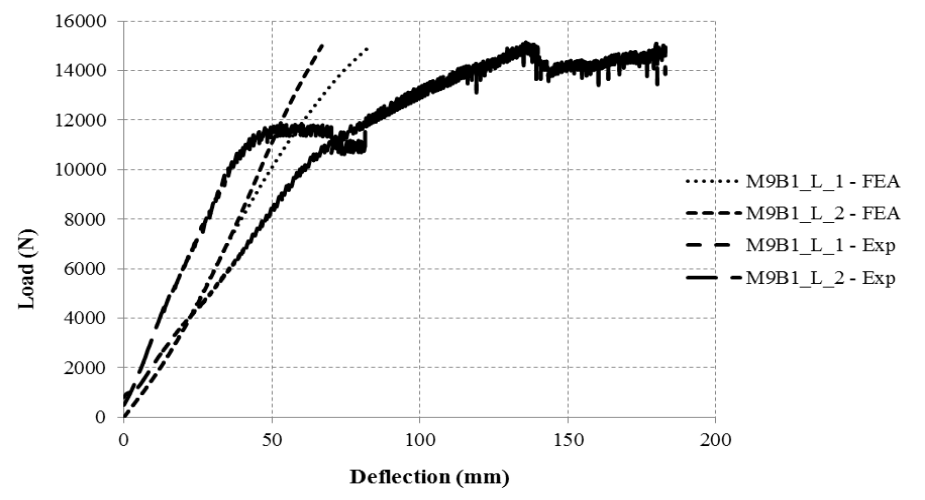

Fig. 11. Load - displacement curves obtained from FEA for M9B1_L_ 1 and M9B1_L 2 under static monotonic loading. Experimental results [3] are also shown for comparison.

Other properties of the connections developed in this study have been obtained from FEA. Initial elastic rotational stiffness $K_{e}$, rotation ductility $\boldsymbol{\mu}_{\text {rotation, }}$ maximum moment $M_{\max }$, and the deflection at maximum load $D_{\max }$ for each connection type are shown in Table 3. Clearly lamina properties have effects on all of these properties. On average, M9B2 connection type has higher initial elastic rotational stiffness and ductility than M9B2 connection type. The maximum moment capacities of both connection types, however, are almost the same.

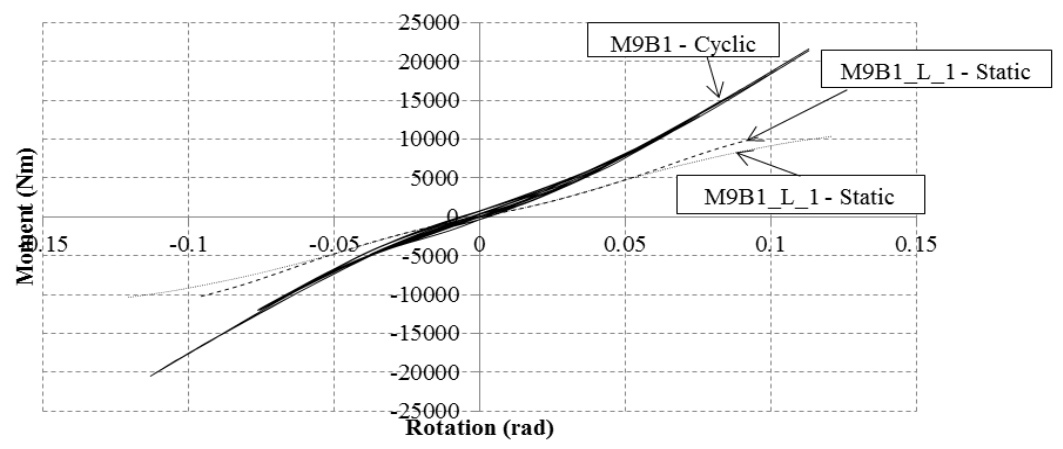

Fig. 12. Moment- rotation curves obtained from FEA for M9B1_L_1 and M9B1_L_2 under static monotonic and cyclic loadings. 


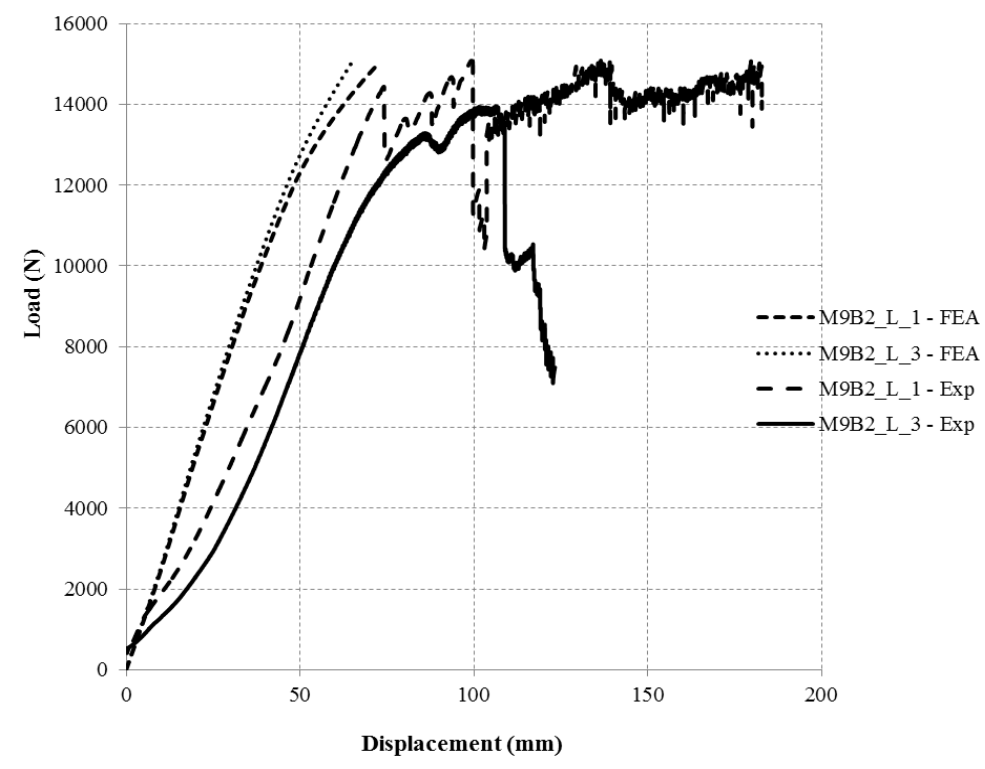

Fig. 13. Load - displacement curves obtained from FEA for M9B2_L_ 1 and M9B2_L_3 under static monotonic loading. Experimental results [3] are also shown for comparison.

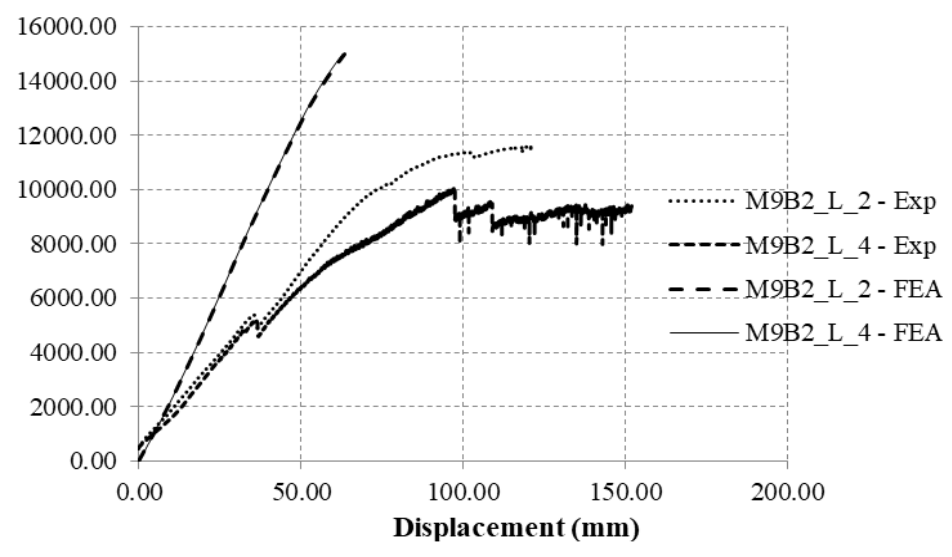

Fig. 14. Load - displacement curves obtained from FEA for M9B2_L_2 and M9B2_L_4 under static monotonic loading. Experimental results [3] are also shown for comparison. 
Table 3. Summary of FEA results of M9B1 and M9B2 connection types under static monotonic loading.

\begin{tabular}{|c|c|c|c|c|}
\hline Identity & $\boldsymbol{K}_{\boldsymbol{e}}(\mathbf{k N m} / \mathbf{r a d})$ & $\boldsymbol{\mu}_{\text {rotation }}$ & $\boldsymbol{M}_{\boldsymbol{m a x}}(\mathbf{k N}-\mathbf{m})$ & $\boldsymbol{D}_{\boldsymbol{P} \max }(\mathbf{m m})$ \\
\hline M9B1_L_1 & 89.1 & 1.2 & 10.35 & 89.23 \\
\hline M9B1_L_2 & 110.6 & 1.0 & 10.35 & 66.88 \\
\hline M9B2_L_1 & 125.0 & 1.4 & 10.35 & 72.4 \\
\hline M9B2_L_2 & 110.1 & 1.0 & 10.43 & 64.5 \\
\hline M9B2_L_3 & 125.0 & 1.6 & 10.20 & 64.6 \\
\hline M9B2_L_4 & 110.0 & 1.0 & 10.35 & 62.8 \\
\hline
\end{tabular}

\section{Summary}

Two types of beam-to-column glulam connection, namely M9B1 and M9B2, have been developed in this study. It has been shown from non-linear finite element analyses and experimental tests that the combination of longitudinal steel rods, steel angle, and lateral steel bars in both types of connection provide the strength of the connections in resisting moment. The strength is obtained from a combined tensile strength of the rods and the bearing strength parallel to the grain of the glulam beam provided that the steel angle has sufficient flexural rigidity. The M9B2 connection type that has more lateral steel bars than M9B1 is more rigid and more ductile than M9B1 connection type.

The authors wish to thank Parahyangan Catholic University for the financial support of this study and Centre of Research and Development Housing and Settlement for laboratory facilities.

\section{References}

1. F. Scheibmair, P. Queneville, "Proceeding of Wood Conference on Timber Engineering (WCTE)",192-201 (2012)

2. E. Leitner, (2011), “A Master of Science Thesis, The Pennsylvania State University, USA", (2011)

3. D. Simanta, B. Suryoatmono, J.A. Tjondro, J. Mekanika, 1, 29-35 (2016)

4. ANSYS, ANSYS Structural Analysis Guide (2009)

5. J. P. Hong, "Three Dimensional Nonlinear Finite Element Model for Single and Multiple Dowel-Type Wood Connections", (2007)

6. American Society for Testing and Materials, ASTM D143-94R07 Standard Test Methods for Small Clear Specimens of Timber (2009)

7. American Society for Testing and Materials, ASTM D5764-97a (Reapproved 2002) Standard Test Methods for Evaluating Dowel-Bearing Strength of Wood and WoodBased Products (2002)

8. International Standard, Timber Structures-Joints made with mechanical fastenersQuasi-static reversed-cyclic test method (ISO 16670) (2003) 